\title{
Development of donor-acceptor copolymers based on dioxocycloalkene-annelated thiophenes as acceptor units for organic photovoltaic materials
}

\author{
Yutaka Ie and Yoshio Aso \\ Organic photovoltaics (OPVs) have attracted considerable attention over the past two decades not only because of their potential \\ for generating renewable energy but also because of their favorable properties, such as low cost, low weight, solution \\ processability and large-area manufacturability. The active layer of OPVs is based on the concept of the bulk-heterojunction \\ configuration, which comprises a blend of a $\pi$-conjugated polymer as an electron donor ( $p$-type) and a fullerene derivative as an \\ electron acceptor (n-type). Donor-acceptor (D-A) copolymers have been utilized as efficient p-type materials in OPVs. In this \\ review, we will focus on a series of dioxocycloalkene-annelated thiophenes as novel acceptor units and summarize photophysical \\ and electrochemical properties of D-A copolymers that contain these acceptor units as well as their OPV performance in \\ combination with $[6,6]$-phenyl- $C_{x}$-butyric acid methyl ester ( $x=61$ or 71 ). These systematic investigations will provide important \\ insight for the development of high-performance D-A-type OPV materials.
}

Polymer Journal (2017) 49, 13-22; doi:10.1038/pj.2016.96; published online 12 October 2016

\section{INTRODUCTION}

The utilization of solar energy for the generation of electricity has become one of the most critical subjects in the renewable energy arena. Organic photovoltaics (OPVs) have attracted considerable attention in both academia and industry because of their advantages compared with solar cells based on inorganic materials, including their low weight, flexibility, low cost and ease of processing. ${ }^{1,2}$ It has been well established that the active layer of OPVs is typically composed of a blend of a $\pi$-conjugated polymer as an electron donor (p-type) and a fullerene derivative as an electron acceptor (n-type), and these materials form an interpenetrating bulk-heterojunction (BHJ) structure to maximize the internal donor-acceptor (D-A) interfacial area for efficient photoinduced charge separation. ${ }^{3-5}$ To increase the power conversion efficiencies (PCEs), with regard to the electronic structure design, $\mathrm{p}$-type materials must have the following properties: (1) a low optical band gap to broaden the absorption range of solar light, which contributes to an increase in the short-circuit current $\left(J_{S C}\right)$, and (2) a low-lying highest occupied molecular orbital (HOMO) energy level to increase the open-circuit voltage $\left(V_{\mathrm{OC}}\right)$, which depends on the difference between the HOMO energy level of the p-type material and the energy level of the lowest unoccupied molecular orbital (LUMO) of the n-type material. Therefore, the development of D-A-conjugated copolymers based on alternating electron-rich and electron-deficient units has been recognized as a straightforward approach to realize an important class of semiconductor materials for OPVs. ${ }^{6,7}$ In this context, a variety of $\pi$-conjugated electron-rich components represented by dithieno $\left[3,2-b: 2^{\prime}, 3^{\prime}-d\right]$ silole $(\text { DTS })^{8}$ and benzo[1,2-b:4,5- $\left.b^{\prime}\right]$ dithiophene $(\text { BDT })^{9}$ have been developed and utilized as donor units in D-A copolymers. On the other hand, the development of new acceptor units is still vital for synthesizing D-A copolymers because effective acceptor units are limited to 2,1,3-benzothiadiazole, ${ }^{8}$ diketopyrrolopyrrole, ${ }^{10}$ thieno[3,4-c] pyrole-4, 6-dione, ${ }^{11}$ thieno[3,4-b] thiophene with electron-withdrawing substitutents $^{12}$ and naphtho[1,2-c:5,6-c']bis[1,2,5]thiadiazole. ${ }^{13}$ We have investigated the development of new electron-accepting materials for $\mathrm{n}$-channel organic field-effect transistors (OFETs) and have applied the developed electron-deficient units to D-A copolymers for OPVs.

We previously reported that the hexafluorocyclopenta $[c]$ thiophene $(\mathbf{F})^{14}$ repeated oligothiophenes $\left(\mathbf{F}_{2}, \mathbf{F}_{4}\right.$ and $\left.\mathbf{F}_{6}\right)$ (Figure 1a) clearly showed a positive shift of the electrochemical reduction potential and red shift of the absorption maximum as the number of the $\mathbf{F}$ units increased. ${ }^{15}$ These results clearly indicate that the annelation of hexafluorocyclopentene at the thiophene rings contributes to an increase in the electron-accepting nature of $\pi$-conjugated systems without disrupting the effective conjugation. Subsequently, we have systematically designed and synthesized a series of electron-deficient thiophene units annelated with a ring that contains the electronwithdrawing functional groups. ${ }^{16-19}$ For example, the LUMO energy level of terthiophene BCB comprised of difluorodioxocyclopenta- $[b]$ thiophene $(\mathbf{B})$ and $-[c]$ thiophene $(\mathbf{C})$ units was estimated to be $-4.17 \mathrm{eV}$; this value is low enough to exhibit an n-type semiconducting nature in OFETs. ${ }^{16}$ To improve the solubility in organic solvents, we synthesized quinquethiophene $\mathrm{BHCHB}$, which consists of the difluorodioxocyclopentene-annelated thiophene and 3-hexylthiophene 
a<smiles>Cc1cc(-c2sc(-c3cc(C)c(C(C)(C)c4cc(C)c(C(C)(C)c5cc6c(s5)C(=O)C(F)(F)C6=O)s4)s3)c3c2C(=O)C(F)(F)C3=O)sc1-c1cc2c(s1)C(=O)C(F)(F)C2=O</smiles>

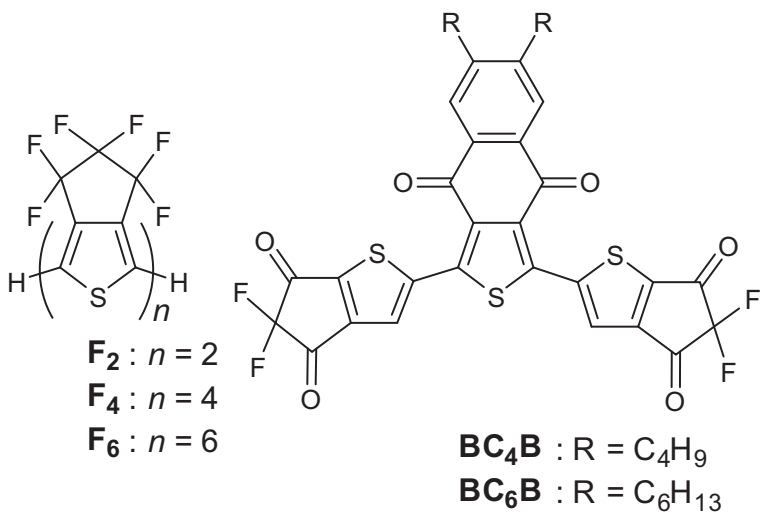

b
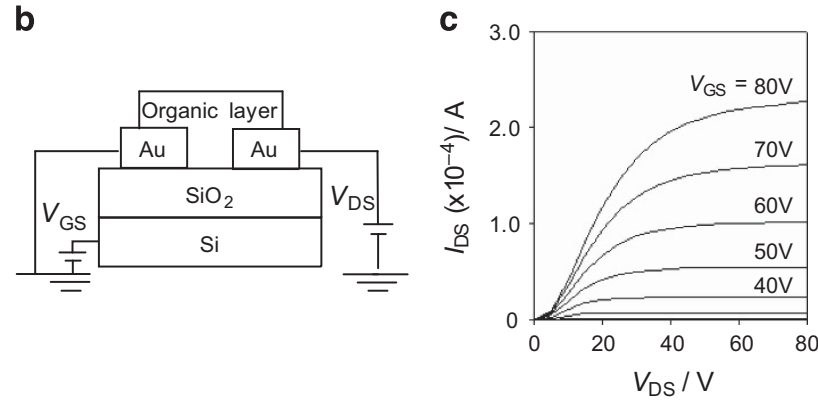

Figure 1 (a) Chemical structures of electron-accepting cycloalkene-annelated oligothiophenes with electron-withdrawing functional groups. (b) Schematic structure of bottom-gate bottom-contact OFET devices. (c) Output characteristics of $\mathbf{B C}_{4} \mathrm{~B}$-based OFET device. A full color version of this figure is available at the Polymer Journal online.

(H). ${ }^{17}$ Although the introduction of electron-donating $\mathbf{H}$ units elevated the LUMO energy level to $-3.54 \mathrm{eV}$, bottom-gate bottomcontact OFETs (Figure 1b) fabricated by spin-coating showed n-channel characteristics with an electron mobility of the order of $10^{-4} \mathrm{~cm}^{2} \mathrm{~V}^{-1} \mathrm{~s}^{-1}$. Furthermore, to decrease the LUMO energy level while retaining good solution processability, we designed dialkylsubstituted electron-deficient naphtho[2,3-c] thiophene-4,9-dione units $\left(\mathbf{C}_{4}\right.$ and $\left.\mathbf{C}_{6}\right)$ to develop $\mathbf{B C}_{4} \mathbf{B}$ and $\mathbf{B C}_{6} \mathbf{B}$. ${ }^{18}$ These molecules showed a substantial improvement of two orders of magnitude in the performance of n-type OFETs (Figure 1c). On account of the effectiveness of our molecular design of electron-transporting OFET materials, we have designed a series of dioxocycloalkene-annelated thiophenes $\left(\mathrm{C}, \mathrm{C}_{\mathrm{h}}, \mathrm{C}_{\mathrm{hy}}, \mathrm{C}_{4}, \mathrm{C}_{6}, \mathrm{C}_{\mathrm{EH}}, \mathrm{C}_{8}\right.$, and $\left.\mathrm{T}_{6}\right)$ to be incorporated into D-A-type copolymers (Figure 2). ${ }^{20-23}$ Several dioxocycloalkeneannelated compounds have also been developed by other groups and utilized as acceptor units in D-A-type copolymers. ${ }^{24-32}$ In this study, to systematically investigate the potential of these acceptor units in the copolymers, the donor units were fixed to DTS and BDT. All the copolymers listed in this review were synthesized by Stille-coupling reactions between dibrominated acceptor units and distannylated donor units.

\section{DIFLUORODIOXOCYCLOPENTA[C]THIOPHENE}

First, we synthesized C-containing D-A copolymers DTS-C and DTS-D-C, where D denotes 3-dodecylthiophene. The target copolymers exhibited moderate solubility in chlorinated solvents, such as chloroform $\left(\mathrm{CHCl}_{3}\right)$, chlorobenzene and $o$-dichlorobenzene $(o-\mathrm{DCB})$, and their number-averaged molecular weights $\left(M_{\mathrm{n}} \mathrm{s}\right)$ were determined to be $6.1 \mathrm{~kg} \mathrm{~mol}^{-1}$ for DTS-C and $15.9 \mathrm{~kg} \mathrm{~mol}^{-1}$ for DTS-D-C, with molar-mass dispersities $\left(D_{\mathrm{M}} \mathrm{s}\right)$ of 1.80 and 1.38, respectively (Figure 3a, Table 1$).^{20}$

Ultraviolet-visible (UV-vis) absorption spectra of DTS-C and DTS-D-C were measured both in $\mathrm{CHCl}_{3}$ solution and as films on quartz plates (Figure $3 \mathrm{~b}$ ). The spectra in $\mathrm{CHCl}_{3}$ solution showed a broad absorption band that covers the region between 400 and $950 \mathrm{~nm}$. Both the copolymers showed two absorption bands, which is a typical feature of the D-A configuration. The weak absorption band at a shorter wavelength corresponds to the local $\pi-\pi^{\star}$ transition of the polymer backbone, whereas the strong main band at longer wavelength is attributed to the intramolecular charge-transfer (CT) transition between the donor and acceptor units. The red shift of the charge-transfer-transition maximum $\left(\lambda_{\max }\right)$ for DTS-C $(721 \mathrm{~nm})$ compared with that of DTS-D-C $(672 \mathrm{~nm})$ implies that the absence of the $\mathbf{D}$ unit in the conjugated backbone contributes to an increase in the D-A nature. The absorption spectra of the polymer films were slightly red shifted compared with those obtained in solution, indicating an increase in planar conformations or a presence of $\pi-\pi$ interchain interactions. The optical HOMO-LUMO energy gaps $\left(\Delta E_{\mathrm{g}}{ }^{{ }^{p p t}} \mathrm{~s}\right)$ for DTS-C and DTS-D-C were determined to be 1.38 and $1.44 \mathrm{eV}$, respectively, from the onset energy of absorption measured for the films. The HOMO energy levels $\left(E_{\mathrm{HOMO}}\right)$ of DTS-C and DTS-D-C were estimated to be -5.51 and $-5.38 \mathrm{eV}$, respectively, from the onset potentials ( $\mathrm{vs} \mathrm{Fc} / \mathrm{Fc}^{+}$) of oxidation observed in the cyclic voltammograms of the films; the energy level of $\mathrm{Fc} / \mathrm{Fc}^{+}$is assumed to be $-4.8 \mathrm{eV}$ below the vacuum level. Note that $E_{\mathrm{HOMO}}$ for DTS-D-C determined by the ionization energy using photoelectron spectroscopy in air (PESA) was $-5.30 \mathrm{eV}$, which is close to the $E_{\mathrm{HOMO}}$ value determined from cyclic voltammetry. From the $E_{\mathrm{HOMO}}$ and $\Delta E_{\mathrm{g}}$ opt values, the LUMO energy levels $\left(E_{\mathrm{LUMO}} \mathrm{s}\right)$ of DTS-C and DTS-D-C were estimated to be -4.13 and $-3.94 \mathrm{eV}$, respectively. On the basis of the onset potentials of the first reduction waves, the $E_{\text {LUMOS }}$ of DTS-C and DTS-D-C were electrochemically estimated to be -3.96 and $-3.73 \mathrm{eV}$, respectively.

The hole mobilities of DTS-C and DTS-D-C were measured using OFETs with a bottom-contact and bottom-gate configuration (Figure 1b). The DTS-D-C film exhibited typical p-type OFET characteristics with a hole mobility of $3.5 \times 10^{-4} \mathrm{~cm}^{2} \mathrm{~V}^{-1} \mathrm{~s}^{-1}$. On the other hand, the DTS-C-based device did not show any OFET response. On the basis of this result and the fact that the $E_{\mathrm{LUMO}}$ of DTS-C is too low lying compared with that $(-3.80 \mathrm{eV})$ of typical n-type OPV materials with [6,6]-phenyl- $\mathrm{C}_{\mathrm{x}}$-butyric acid methyl ester $\left(\mathrm{PC}_{\mathrm{x}} \mathrm{BM}, x=61\right.$ or 71$)$, we only investigated the photovoltaic characteristics of DTS-D-C.

The OPV performance was investigated using a BHJ solar cell with a standard configuration of glass/indium tin oxide (ITO)/ poly(3,4-ethylenedioxythiophene):poly(styrenesulfonate)(PEDOT:PSS)/ DTS-D-C:PC ${ }_{71} \mathrm{BM}(1: 2 \mathrm{w} / \mathrm{w}) / \mathrm{Al}$. The active $\mathrm{BHJ}$ layer was prepared by spin coating an $o$-DCB solution of a DTS-D-C/PC ${ }_{71} \mathrm{BM}$ blend. This device showed typical OPV characteristics under AM 1.5G simulated solar illumination $\left(100 \mathrm{~mW} \mathrm{~cm}^{-2}\right)$ with a PCE of $0.77 \%$, a $V_{\mathrm{OC}}$ of 
<smiles>CSCC1(F)C(=O)c2cscc2C1(F)F</smiles>

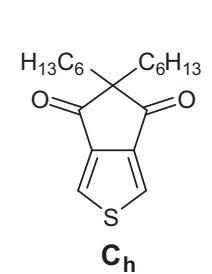

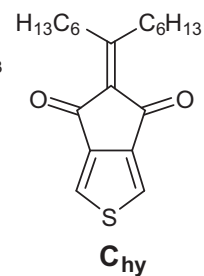<smiles>[R]c1cc2c(cc1[R])C(=O)c1cscc1C2=O</smiles>

$\mathrm{C}_{4}: \mathrm{R}=\mathrm{C}_{4} \mathrm{H}_{9}$ $\mathrm{C}_{6}: \mathrm{R}=\mathrm{C}_{6} \mathrm{H}_{13}$ $\mathrm{C}_{\mathrm{E}}: \mathrm{R}=$ 2-ethylhexyl

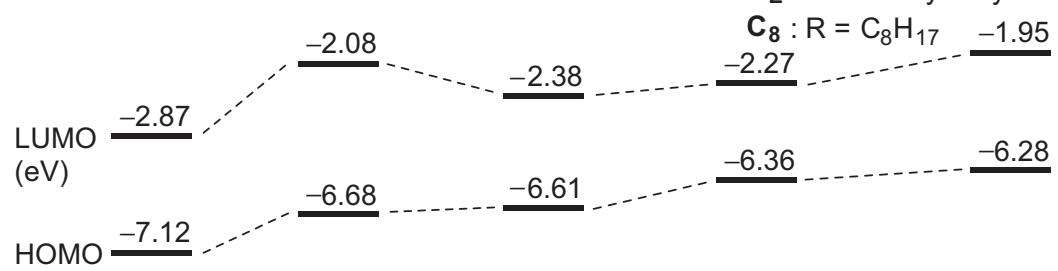

$(\mathrm{eV})$

Figure 2 Our developed dioxocycloalkene-annelated thiophenes. Density functional theory calculations were performed at the B3LYP/6-31G(d, p) level. All the solubilizing alkyl groups were replaced with methyl groups to simplify the calculations.

\section{a}

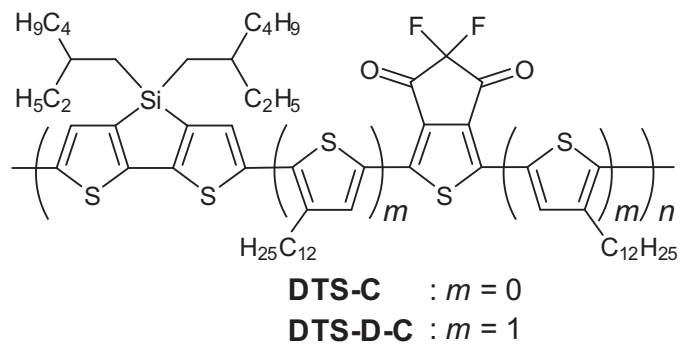

b

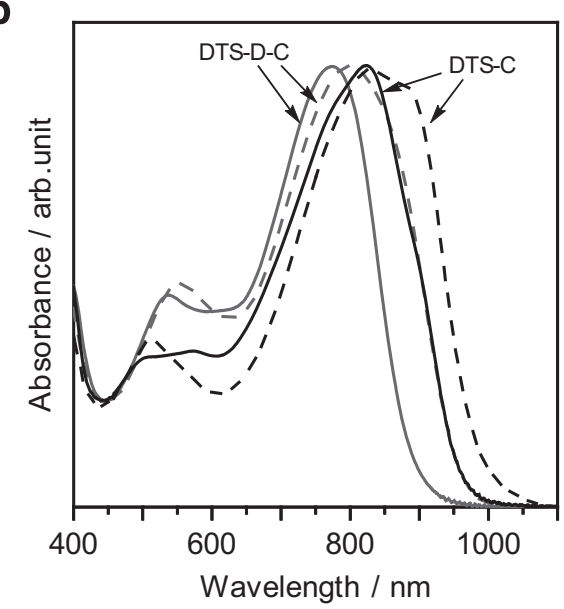

Figure 3 (a) Chemical structures of DTS-C and DTS-D-C. (b) UV-vis absorption spectra of DTS-C (black) and DTS-D-C (blue) in $\mathrm{CHCl}_{3}$ solution (solid line) and as films (dashed line). A full color version of this figure is available at the Polymer Journal online.

$0.88 \mathrm{~V}$, a $J_{\mathrm{SC}}$ of $1.9 \mathrm{~mA} \mathrm{~cm}^{-2}$ and a fill factor (FF) of 0.46 (Table 2). The value of $J_{S C}$ is relatively low, which results in the poor PCE value, although the $V_{\mathrm{OC}}$ and FF values are reasonably high. We rationalized that the low-lying LUMO energy level of DTS-D-C prevented efficient charge separation between the copolymers and $\mathrm{PC}_{71} \mathrm{BM}$, which resulted in the low $J_{\mathrm{SC}}$.

\section{DIHEXYLDIOXOCYCLOPENTA[C]THIOPHENE AND (DIHEXYLMETHYLIDENE)DIOXOCYCLOPENTA[C]THIOPHENE}

As described in the preceding section, owing to the insufficiency of solubilizing alkyl groups in the conjugated backbone, the $M_{\mathrm{n}}$ of DTS-C was limited to $6.1 \mathrm{~kg} \mathrm{~mol}^{-1} .^{20}$ More importantly, the strong electron-withdrawing nature of the $\mathbf{C}$ unit led to an excessive decrease in the LUMO energy level of the resulting D-A copolymers. To overcome this, we decided to introduce solubilizing groups and to concomitantly fine-tune the orbital energy levels by replacing the fluorine substituents in the $\mathbf{C}$ unit. Based on this concept, we designed dihexyldioxocyclopenta $[c]$ thiophene $\left(\mathbf{C}_{\mathbf{h}}\right)$ and (dihexylmethylidene) dioxocyclopenta $[c]$ thiophene $\left(\mathbf{C}_{\mathbf{h y}}\right){ }^{21}$ In the $\mathbf{C}_{\mathbf{h}}$ unit, we substituted the fluorine atoms of the $\mathrm{C}$ unit with hexyl groups while retaining a tetrahedral carbon atom; the $\mathbf{C}_{\mathbf{h y}}$ unit is a planar structure with a dihexylmethylidene group (Figure 2). Density functional theory calculations indicated that the replacement of fluorine atoms with alkyl groups resulted in an increase of both the HOMO and LUMO energy levels. To investigate the effectiveness of these modified structures as acceptor units, we developed new D-A copolymers with the DTS donor unit (DTS- $\mathbf{C}_{\mathbf{h}}$ and DTS- $\mathbf{C}_{\mathbf{h y}}$ ) and donor-part-extended copolymers (DTS-T- $\mathbf{C}_{\mathbf{h}}$ and DTS-T- $\mathbf{C}_{\mathbf{h y}}$ ) (Figure $4 \mathrm{a}$ ). Owing to the solubilizing alkyl groups in the $\mathbf{C}_{\mathbf{h}}$ and $\mathbf{C}_{\mathbf{h y}}$ units, we can adopt pristine thiophene $(\mathbf{T})$ as the $\pi$-bridge instead of 3 -dodecylthiophene $(\mathbf{D})$ in DTS-D-C, which might induce better $\pi-\pi$ interactions in BHJ active layers. The $M_{\mathrm{n}}$ and $D_{\mathrm{M}}$ values were measured using high-temperature gel permeation chromatography at $140{ }^{\circ} \mathrm{C}$ with $o-\mathrm{DCB}$ as an eluent; DTS- $C_{h}$, DTS-T- $C_{h}$, DTS- $C_{h y}$ and DTS-T- $C_{h y}$ had $M_{\mathrm{n}}$ s of 8.3, 11.7, 6.3 and $7.9 \mathrm{~kg} \mathrm{~mol}^{-1}$, respectively, and $D_{\mathrm{M}} \mathrm{s}$ of $1.6,2.0,1.7$ and 2.5 , respectively. The dialkylated tetrahedral structure increased the solubility and thus the $M_{\mathrm{n}} \mathrm{s}$ of $\mathbf{C}_{\mathbf{h}}$-based copolymers were higher than those of $\mathbf{C}_{\mathbf{h y}}$-based copolymers.

The red shift observed in the absorption maxima of DTS- $\mathbf{C}_{\mathbf{h}}$ and DTS- $C_{h y}$ in solution compared with those of DTS-T- $C_{h}$ and DTS-T- $\mathbf{C}_{\mathbf{h y}}$ indicated that the absence of $\mathbf{T}$ between the donor and acceptor units contributes to an increase in the D-A characteristics (Figure 4b). This trend is similar to what is observed in the DTS-D-C and DTS-C systems, as described above. The shoulder at approxi-

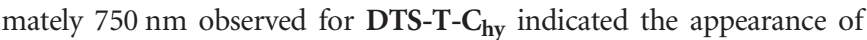
interchain $\pi-\pi$ interactions even when dilute solutions were used. 
Table 1 Characteristics of copolymers

\begin{tabular}{|c|c|c|c|c|c|c|}
\hline Copolymers & $\mathrm{M}_{n} / \mathrm{kg} \mathrm{mol}^{-1 \mathrm{a}}$ & $\mathrm{D}_{M^{\mathrm{a}}}$ & $\lambda_{\max } / n m^{\mathrm{b}}$ & $\Delta \mathrm{E}_{g}$ opt/eV & $\mathrm{E}_{\text {HOMd }} \mathrm{eV}^{\mathrm{d}}$ & $\mathrm{E}_{\text {LUMdeV }}$ \\
\hline DTS-C ${ }^{f}$ & 6.1 & 1.80 & 724 & 1.38 & $(-5.51)$ & $-4.13(-3.96)$ \\
\hline DTS-D-C ${ }^{f}$ & 15.9 & 1.38 & 672 & 1.44 & $-5.30(-5.38)$ & $-3.94(-3.73)$ \\
\hline DTS-C $\mathrm{h}^{\mathrm{g}}$ & $8.3^{\mathrm{h}}$ & $1.6^{\mathrm{h}}$ & 630,680 & 1.68 & $-5.40(-5.45)$ & $-3.72(-3.63)$ \\
\hline DTS-T- $C_{h}{ }^{g}$ & $11.7^{\mathrm{h}}$ & $2.0^{h}$ & 615 (sh), 662 & 1.73 & $-5.16(-5.21)$ & $-3.43(-3.41)$ \\
\hline DTS- $C_{h y}{ }^{g}$ & $6.3^{\mathrm{h}}$ & $1.7^{\mathrm{h}}$ & 638,681 (sh) & 1.57 & $-5.27(-5.35)$ & $-3.70(-3.60)$ \\
\hline DTS-T-C ${ }_{\text {hy }}{ }^{g}$ & $7.9^{h}$ & $2.5^{\mathrm{h}}$ & 626,725 (sh) & 1.56 & $-5.02(-5.08)$ & $-3.46(-3.43)$ \\
\hline DTS-C $6-\mathrm{L}^{\mathrm{i}}$ & 19.5 & 1.51 & 600 & 1.63 & $-5.19(-5.33)$ & $-3.56(-3.52)$ \\
\hline DTS-T 6 & 19.1 & 1.46 & 581 & 1.72 & $-5.21(-5.33)$ & $-3.49(-3.39)$ \\
\hline BDT-C ${ }_{6}^{i}$ & 18.6 & 2.38 & 543 & 1.86 & $-5.23(-5.40)$ & $-3.37(-3.50)$ \\
\hline BDT-T $6{ }^{i}$ & 18.8 & 3.53 & 539 & 1.92 & $-5.32(-5.41)$ & $-3.40(-3.45)$ \\
\hline DTS-C ${ }_{4}^{j}$ & 41.5 & 2.0 & 606 & 1.63 & -5.33 & -3.70 \\
\hline DTS-C ${ }_{6}^{j}$ & 42.8 & 1.7 & 610 & 1.62 & -5.25 & -3.63 \\
\hline DTS- $C_{E H^{j}}$ & 53.4 & 1.7 & 611 & 1.62 & -5.27 & -3.65 \\
\hline DTS-C ${ }_{8}{ }^{j}$ & 46.3 & 2.0 & 606 & 1.64 & -5.27 & -3.63 \\
\hline
\end{tabular}

Abbreviations: BDT, benzo[1,2-b:4,5- $\left.b^{\prime}\right]$ dithiophene; DTS, dithieno[3,2-b:2', $\left.3^{\prime}-d\right]$ silole; HOMO, highest occupied molecular orbital; LUMO, lowest unoccupied molecular orbital.

${ }^{\mathrm{a}} \mathrm{CHCl}_{3}$ as an eluent measured at room temperature.

In $\mathrm{CHCl}_{3}$ solution.

'Determined by the onset of the UV-vis absorption spectrum in the film.

${ }^{d}$ Determined by PESA. The number in parentheses was determined from CV.

${ }^{e} E_{\mathrm{LUMO}}=E_{\mathrm{HOMO}}+\Delta E_{\mathrm{g}} \mathrm{opt}$. The number in parentheses was determined from $\mathrm{CV}$.

fle et al. ${ }^{20}$

gHuang et al. ${ }^{21}$

${ }^{\mathrm{h}} \mathrm{O}-\mathrm{DCB}$ as an eluent measured at $1400^{\circ} \mathrm{C}$

ile et al. ${ }^{22}$

jHuang et al.23

Although the absorption spectra of DTS- $\mathbf{C}_{\mathbf{h}}$ and DTS-T- $\mathbf{C}_{\mathbf{h}}$ in the films showed no noticeable difference from their corresponding solution spectra, the CT transition bands of DTS- $\mathbf{C}_{\mathbf{h y}}$ and DTS-T- $\mathbf{C}_{\mathbf{h y}}$ in the films clearly broadened and were red shifted compared with those observed in solution. This result indicates that the coplanar conformation between the dihexylmethylidene group and the cyclopenta $[c]$ thiophene skeleton may facilitate cofacial interchain aggregations. As a result, the $\Delta E_{\mathrm{g}}{ }^{\text {opt }_{\mathrm{S}}}$ of DTS-C $\mathrm{hy}(1.57 \mathrm{eV})$ and DTS-T- $\mathbf{C}_{\text {hy }}(1.56 \mathrm{eV})$ are smaller than those of DTS- $\mathbf{C}_{\mathbf{h}}(1.68 \mathrm{eV})$ and DTS-T- $\mathbf{C}_{\mathbf{h}}(1.73 \mathrm{eV})$. On the other hand, as summarized in Table 1 , both the low-lying $E_{\mathrm{LUMO}}$ and $E_{\mathrm{HOMO}}$ of DTS-C $\mathbf{C}_{\mathbf{h}}$ and DTS-C $\mathbf{C}_{\mathbf{h y}}$ compared with those of DTS-T- $\mathbf{C}_{\mathbf{h}}$ and DTS-T- $\mathbf{C}_{\mathbf{h y}}$ indicate that the absence of thiophene between the donor and acceptor units contributes to an increase in the electron-accepting characteristics of the conjugated backbones. It should also be mentioned that, as we expected, the $E_{\mathrm{LUMO}}$ of all these copolymers are higher than those of DTS-C and DTS-D-C, ${ }^{20}$ which can be attributed to the relatively weak electron-accepting ability of the $\mathbf{C}_{\mathbf{h}}$ and $\mathbf{C}_{\mathbf{h y}}$ units compared with the $\mathbf{C}$ unit.

To investigate the OPV performances of the copolymers, BHJ solar cells were fabricated with a typical layered configuration of glass/ITO/ PEDOT:PSS/active layer/Ca/Al. As summarized in Table 2, all the devices composed of the copolymer and $\mathrm{PC}_{61} \mathrm{BM}$ showed photovoltaic behavior. The OPV device based on DTS- $\mathrm{C}_{\mathrm{h}}$ showed a markedly high $V_{\mathrm{OC}}$ of $0.95 \mathrm{~V}$. This result can be attributed to the relatively low-lying HOMO energy level of DTS- $\mathbf{C}_{\mathbf{h}}$ because the $V_{\mathrm{OC}}$ of OPVs is proportional to the difference between the HOMO energy level of the donor and the LUMO energy level of the acceptor. ${ }^{33}$ In fact, the trend of the observed $V_{\mathrm{OC}}$ values is in qualitative agreement with the relative HOMO energy levels of the donor polymers (Figure 4c). The devices based on DTS-T- $\mathbf{C}_{\mathbf{h}}$ and DTS-T- $\mathbf{C}_{\mathbf{h y}}$ showed higher Jsc and FF values than the devices based on DTS- $\mathbf{C}_{\mathbf{h}}$ and DTS- $\mathbf{C}_{\mathbf{h y}}$. This phenomenon is consistent with the fact that the balanced ambipolar (hole and electron) mobilities of DTS-T- $\mathrm{C}_{\mathbf{h}} / \mathrm{PC}_{61} \mathrm{BM}$ and DTS-T- $\mathrm{C}_{\mathrm{hy}} / \mathrm{PC}_{61} \mathrm{BM}$ blend films were observed in space-charge-limited current (SCLC) measurements, whereas DTS- $\mathrm{C}_{\mathbf{h}} / \mathrm{PC}_{61} \mathrm{BM}$ and DTS- $\mathrm{C}_{\text {hy }} / \mathrm{PC}_{61} \mathrm{BM}$ blend films exhibited only unipolar (hole) mobilities. Overall, the DTS-T- $\mathbf{C}_{\mathbf{h}^{-}}$and DTS-T- $\mathbf{C}_{\mathbf{h y}}$-based devices exhibited moderate PCEs of $2.68 \%$ and $2.65 \%$, respectively.

The active layers fabricated from a blend of DTS-T- $\mathbf{C}_{\mathbf{h}}$ and DTS-T- $\mathrm{C}_{\text {hy }}$ with $\mathrm{PC}_{71} \mathrm{BM}$ showed improved PCEs of 2.84 and $3.43 \%$, respectively (Figure $4 \mathrm{~d}$ and Table 2). This improvement of PCEs is generally attributed to the increased absorption of $\mathrm{PC}_{71} \mathrm{BM}$ in the visible region compared with $\mathrm{PC}_{61} \mathrm{BM}$, which resulted in improved $J_{\text {SC }}$ values. Furthermore, although the addition of 3\% 1,8-diiodooctane $(\mathrm{DIO})^{34}$ to the processing solvent for the DTS-T-Chy -based device did not considerably improve the OPV performance, the addition of $3 \%$ DIO to $o$-DCB for DTS-T- $\mathrm{C}_{\mathbf{h}} / \mathrm{PC}_{71} \mathrm{BM}$ led to a drastic increase of Jsc $\left(10.1 \mathrm{~mA} \mathrm{~cm}^{-2}\right)$ and $\mathrm{FF}(0.64)$ while the $V_{\mathrm{OC}}$ remained at a high level $(0.80 \mathrm{~V})$; this resulted in a substantial improvement of the overall device performance to a PCE of $5.17 \%$. The X-ray diffraction patterns of DTS-T- $\mathrm{C}_{\mathrm{h}} / \mathrm{PC}_{71} \mathrm{BM}$ films showed a broad peak at approximately $2 \theta=20^{\circ}$, which is ascribed to $\pi-\pi$ stacking between the backbones of the copolymers, irrespective of whether DIO was added during processing. This phenomenon is rationalized by possible cofacial interchain aggregations derived from the coplanar backbone conformation of the copolymer, and the presence of these aggregations does not depend on the addition of DIO. On the other hand, the atomic force microscopic images of the DTS-T- $\mathbf{C}_{\mathbf{h}}$-containing blend films clearly indicated that the addition of DIO caused a substantial increase in the domain size with an average roughness $\left(R_{\mathrm{a}}\right)$ value of $2.25 \mathrm{~nm}$, which differs from the value of $1.90 \mathrm{~nm}$ for the blend film without DIO (Figure 4e). This result indicates that the addition of DIO contributed to the formation of appropriate phase separation in the blend films.

DIHEXYL-SUBSTITUTED NAPHTHO[2,3-C]THIOPHENE-4,9-DIONE AND 4H,8H-BENZO[1,2-C:4,5-C]DITHIOPHENE-4,8-DIONE

As an alternative way of tuning the energy level of DTS-C by replacing the strongly electron-deficient $\mathbf{C}$ unit, we focused on the $\mathbf{C}_{\mathbf{6}}$ unit 


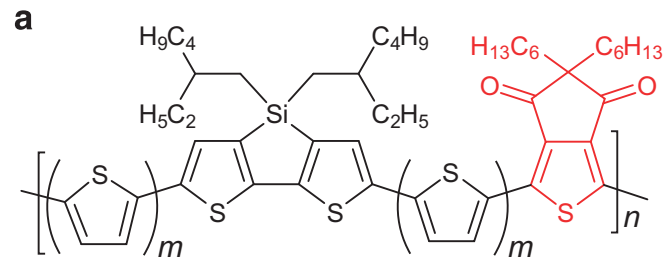

C
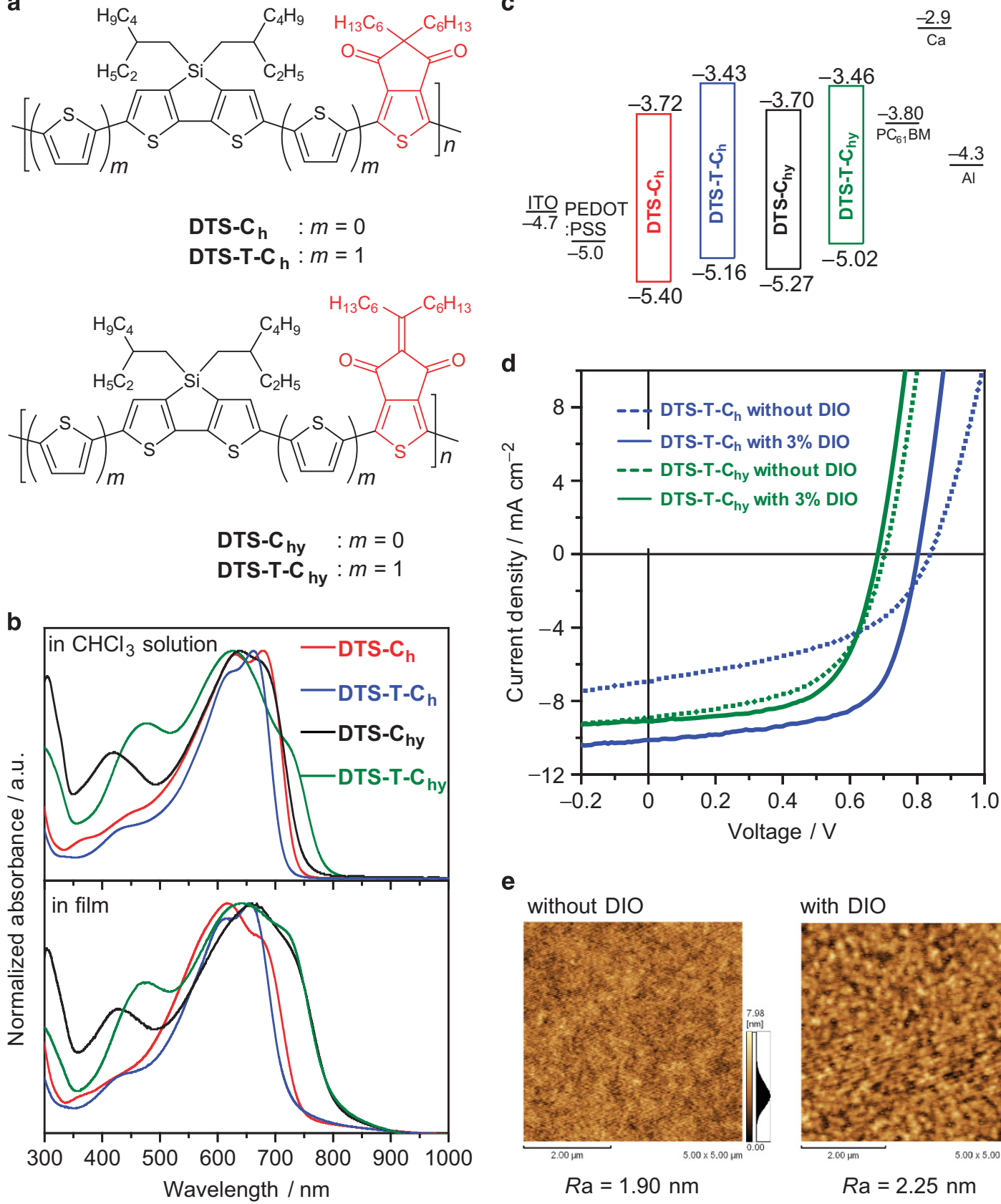

e

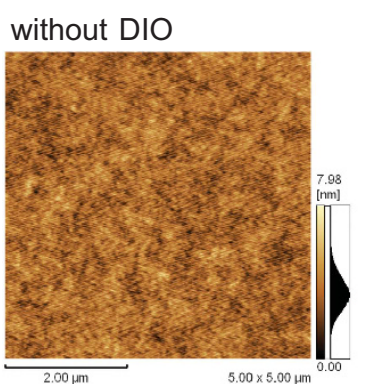

$\mathrm{Ra}=1.90 \mathrm{~nm}$

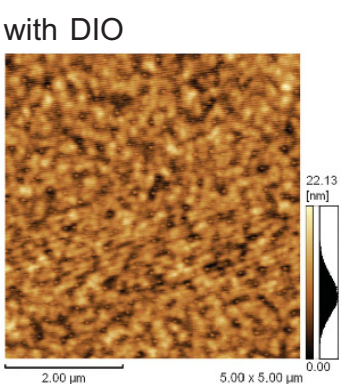

$R a=2.25 \mathrm{~nm}$

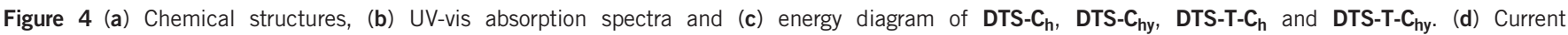
density-voltage curves of the OPV devices based on blend of DTS-T-C and DTS-T- $C_{h y} /$ PC ${ }_{71}$ BM. (e) Atomic force microscopic height images of DTS-T- $C_{h} / P_{71} B M$ without DIO and with $3 \%$ DIO.

because the replacement of $\mathbf{C}$ with $\mathbf{C}_{6}$ in a $\mathbf{B C B}$ system resulted in an increase of approximately $0.3 \mathrm{eV}$ in the LUMO energy level for $\mathbf{B C}_{6} \mathbf{B}$ (the structures are shown in Figure 1a). ${ }^{18}$ This result indicates that the electron-accepting ability of $\mathbf{C}_{6}$ is weaker than that of $\mathbf{C}$. To investigate the influence of the annelated dihexyl-substituted benzene unit on the electronic properties and OPV performance of D-A copolymers, we also designed 5,7-dihexyl-4H,8H-benzo[1,2-c:4,5-c] dithiophene-4, 8 -dione $\left(\mathbf{T}_{\mathbf{6}}\right)$ as a new electron-deficient unit (Figure 2 ). Density functional theory calculations suggest that the frontier orbital energy levels of both $\mathbf{C}_{6}$ and $\mathbf{T}_{6}$ are comparable to those of the $\mathbf{C}_{h}$ and $\mathbf{C}_{h y}$ units (Figure 2). Moreover, their extended $\pi$-systems compared with $\mathbf{C}_{\mathbf{h}}$ and $\mathbf{C}_{\mathrm{hy}}$ are expected to facilitate cofacial interchain aggregations of resulting D-A copolymers and hence to enhance carrier transport in blend OPV films. We therefore developed copolymers DTS-C ${ }_{6}$, DTS-T $_{6}$, BDT-C $_{6}$ and BDT-T 6 (Figure $5 \mathrm{a}$ ). ${ }^{22}$ Using analytical gel permeation chromatography with $\mathrm{CHCl}_{3}$ as an eluent, DTS- $\mathbf{C}_{6}$, DTS-T $_{6}$, BDT-C $_{6}$ and BDT-T 6 have $M_{\mathrm{n}} \mathrm{s}$ of 19.5, 19.1, 18.6 and $18.8 \mathrm{~kg} \mathrm{~mol}^{-1}$, respectively, and $D_{\mathrm{M}^{\mathrm{S}}}$ of $1.51,1.46,2.38$, and 3.53 , respectively (Table 1). Note that DTS-C 6 with an $M_{\mathrm{n}}$ of $19.5 \mathrm{~kg} \mathrm{~mol}^{-1}$ is hereafter designated DTS-C $\mathbf{C}_{6}-\mathbf{L}$.

As shown in Figure $5 \mathrm{~b}$ and Table 1 , the absorption maxima of DTS-containing copolymers in $\mathrm{CHCl}_{3}$ solution $\left(600 \mathrm{~nm}\right.$ for DTS- $\mathrm{C}_{6}$ and $581 \mathrm{~nm}$ for DTS-T $_{6}$ ) are red shifted compared with those of BDT-containing copolymers $\left(543 \mathrm{~nm}\right.$ for BDT-C $_{6}$ and $539 \mathrm{~nm}$ for 
Table 2 OPV characteristics of copolymers

\begin{tabular}{|c|c|c|c|c|c|c|}
\hline Blend films & Processed solvent & Blend ratio (w:w) & $v_{o d V}$ & $\mathrm{~J}_{S C} / m A \mathrm{~cm}^{-2}$ & $F F$ & PCE/\% \\
\hline DTS-C $\mathrm{C}_{\mathrm{h}} / \mathrm{PC}_{61} \mathrm{BM}^{\mathrm{b}}$ & $o-D C B$ & $1: 2$ & 0.95 & 5.83 & 0.26 & 1.44 \\
\hline DTS-C $C_{h y} / P_{61} \mathrm{BM}^{b}$ & o-DCB & $1: 2$ & 0.85 & 3.91 & 0.41 & 1.36 \\
\hline DTS-T-C $C_{\text {hy }} / P_{61}$ BM $^{b}$ & o-DCB & $1: 2$ & 0.69 & 7.50 & 0.51 & 2.65 \\
\hline DTS-T- $\mathrm{C}_{\mathbf{h}} / \mathrm{PC}_{71} \mathrm{BM}^{\mathrm{b}}$ & o-DCB & $1: 1.5$ & 0.84 & 6.95 & 0.49 & 2.84 \\
\hline DTS-T- $C_{\text {hy }} / P_{71}$ BM $^{b}$ & o-DCB & $1: 2$ & 0.70 & 8.89 & 0.55 & 3.43 \\
\hline DTS-T-C $C_{\text {hy }} / \mathrm{PC}_{71} \mathrm{BM}^{\mathrm{b}}$ & $\begin{array}{c}o-D C B \\
3 \% \text { DIO }\end{array}$ & $1: 2$ & 0.68 & 9.10 & 0.61 & 3.79 \\
\hline DTS-C C $_{6}-\mathrm{L} \mathrm{PC}_{61} \mathrm{BM}^{\mathrm{C}}$ & $\mathrm{CB}$ & $1: 2$ & 0.90 & 8.96 & 0.51 & 4.12 \\
\hline DTS-T ${ }_{6} / \mathrm{PC}_{61} \mathrm{BM}^{\mathrm{c}}$ & $\mathrm{CB}$ & $1: 2$ & 0.98 & 6.01 & 0.46 & 2.70 \\
\hline BDT-C $\mathrm{C}_{6} / \mathrm{PC}_{61} \mathrm{BM}^{\mathrm{c}}$ & $\mathrm{CB}$ & $1: 2$ & 0.83 & 1.81 & 0.30 & 0.45 \\
\hline DTS-C $6 / \mathrm{PC}_{71} \mathrm{BM}(82 \mathrm{~nm})^{\mathrm{d}, \mathrm{e}}$ & o-DCB & $1: 2$ & 0.90 & 10.59 & 0.55 & 5.21 \\
\hline DTS-C $C_{E H} / P_{71} B M(80 \mathrm{~nm})^{\mathrm{d}, \mathrm{e}}$ & o-DCB & $1: 2$ & 0.94 & 9.46 & 0.58 & 5.15 \\
\hline DTS-C $\mathrm{C}_{8} / \mathrm{PC}_{71} \mathrm{BM}(80 \mathrm{~nm})^{\mathrm{d}, \mathrm{e}}$ & o-DCB & $1: 2$ & 0.88 & 5.00 & 0.53 & 2.35 \\
\hline DTS-C ${ }_{6} /$ PC $_{71}$ BM $(82 \mathrm{~nm})^{\mathrm{d}, \mathrm{e}}$ & $\begin{array}{c}o-\mathrm{DCB} \\
3 \% \mathrm{DIO}\end{array}$ & $1: 2$ & 0.87 & 9.88 & 0.65 & 5.56 \\
\hline DTS-C C $_{6}$ PC $_{71}$ BM $(190 \mathrm{~nm})^{\mathrm{d}, \mathrm{e}}$ & $\begin{array}{l}\mathrm{CHCl}_{3} \\
3 \% \mathrm{DIO}\end{array}$ & $1: 2$ & 0.85 & 15.54 & 0.41 & 5.42 \\
\hline DTS-C $6 / \mathrm{PC}_{71} \mathrm{BM}(79 \mathrm{~nm})^{\mathrm{d}, \mathrm{e}}$ & $\begin{array}{c}\text { o-DCB: } \mathrm{CHCl}_{3}(4: 1) \\
3 \% \mathrm{DIO}\end{array}$ & $1: 2$ & 0.86 & 14.39 & 0.64 & 7.85 \\
\hline
\end{tabular}

Abbreviations: BDT, benzo[1,2-b:4,5-b']dithiophene; CB, chlorobenzene; DIO, 1,8-diiodooctane; DTS, dithieno[3,2-b:2',3'-d]silole; FF, fill factor; OPV, organic photovoltaic; PCE, power conversion efficiency.

le et al. 20

bHuang et al.

'le et al. ${ }^{22}$ inuang et al. ${ }^{23}$

eThe number in parentheses is the thickness of the active layer.

BDT-T 6 ). A similar trend has also been observed for other BDT- and DTS-based copolymers. ${ }^{35}$ The absorption spectra of the copolymer films were red shifted compared with those in solution, which indicates the increase in planar conformations and/or the presence of $\pi-\pi$ interchain interactions in the solid state. From the onset of the UV-vis absorption spectra of the films, the $\Delta E_{\mathrm{g}}$ opt $_{\mathrm{S}}$ of DTS-C 6 , DTS-T $_{6}$, BDT-C $_{6}$ and BDT-T 6 were estimated to be 1.63, 1.72, 1.86 and $1.92 \mathrm{eV}$, respectively. These values indicate that the $\mathbf{C}_{6}$ unit contributes to the narrowed $\Delta E_{\mathrm{g}}$ opt of D-A copolymers, compared with the $\mathbf{T}_{6}$ unit.

The ionization potentials evaluated by PESA for DTS- $\mathrm{C}_{6}$, DTS-T $_{6}$, BDT- $\mathrm{C}_{6}$ and BDT-T ${ }_{6}$ correspond to $E_{\mathrm{HOMO}}$ of $-5.19,-5.21,-5.23$ and $-5.32 \mathrm{eV}$, respectively. Considering the differences in these energy levels, the overall behavior of the $E_{\mathrm{HOMO}}$ primarily depends on the electron-donating ability of the BDT and DTS units. The $E_{\mathrm{LUMO}}$ s of these copolymers (estimated from cyclic voltammetry (Table 1)) are approximately $0.2-0.3 \mathrm{eV}$ higher than the $E_{\mathrm{LUMO}}$ of DTS-D-C, so an improvement in the charge separation between these copolymers and fullerene derivatives is expected (Figure $5 c$ ).

The OPV performance of the copolymers was investigated in $\mathrm{BHJ}$ solar cells with a conventional device configuration of ITO/PEDOT: $\mathrm{PSS} /$ copolymer: $\mathrm{PC}_{61} \mathrm{BM} / \mathrm{Al}$. All the copolymers showed typical photovoltaic responses, and the representative photovoltaic parameters are summarized in Table 2 . All the devices exhibited relatively high $V_{\mathrm{OC}}$ values $(0.83-0.98 \mathrm{~V})$, which reflects the low-lying $E_{\mathrm{HOMO}}$ of the copolymers. Interestingly, depending on the chemical structures of the D-A copolymers, the devices exhibited significant differences in their PCEs, which is primarily a reflection of the different $J_{S C}$ values: the

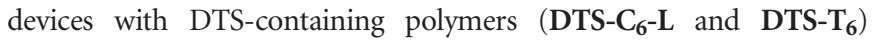
exhibited good PCEs of $4.12 \%$ and $2.70 \%$, respectively, whereas those with BDT-containing polymers $\left(\right.$ BDT-C$_{\mathbf{6}}$ and BDT-T $_{6}$ ) exhibited poor PCEs of $<1 \%$. This disparity between these polymers can be attributed to a difference in surface morphology; surface atomic force microscopic images showed that the blends of DTS-containing polymers formed aggregated nanometer-scale domains without apparent phase segregation, whereas the blends of BDT-containing polymers formed large segregated domains. These results indicate that the morphologies of the blends of DTS-containing polymers are beneficial for efficient charge separation and charge transport, which resulted in the observed difference in the PCEs. Furthermore, the device with DTS- $\mathrm{C}_{6}$-L had a higher PCE value compared with the device with DTS-T 6 , which was mainly attributed to the $J_{S C}$ value. This high $J_{S C}$ value is attributed to the higher field-effect hole mobility of DTS- $\mathbf{C}_{\mathbf{6}}-\mathrm{L}$ $\left(1.4 \times 10^{-4} \mathrm{~cm}^{2} \mathrm{~V}^{-1} \mathrm{~s}^{-1}\right)$ than of DTS-T $6\left(3.2 \times 10^{-5} \mathrm{~cm}^{2} \mathrm{~V}^{-1} \mathrm{~s}^{-1}\right)$.

\section{FINE TUNING OF DIALKYL-SUBSTITUTED NAPHTHO[2,3-C] THIOPHENE-4,9-DIONE}

To further investigate the photovoltaic performance of DTS- $\mathrm{C}_{6}-\mathrm{L}$, $\mathrm{OPV}$ devices were fabricated using $\mathrm{PC}_{71} \mathrm{BM}$ as the n-type material with the device structure of glass/ITO/PEDOT:PSS/ DTS-C ${ }_{6}-\mathrm{L}$ : 
a
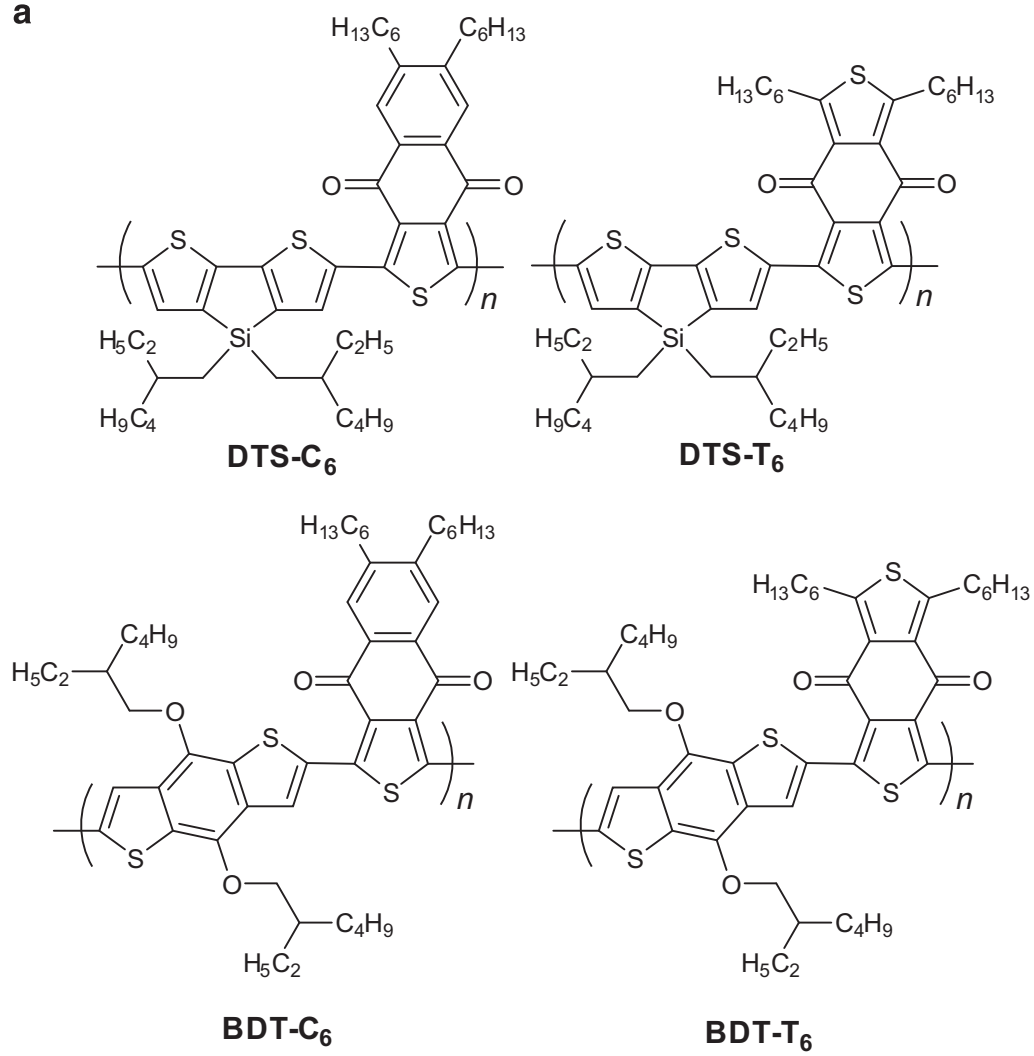

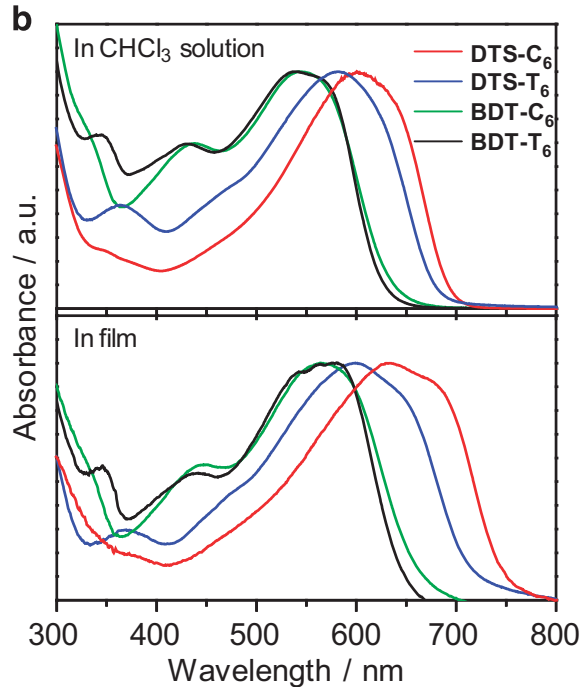

C

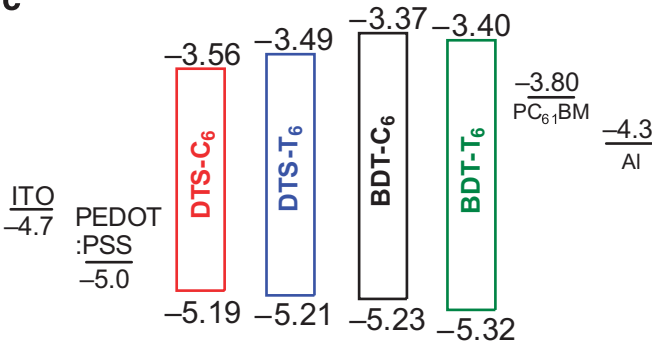

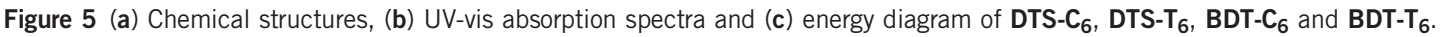

$\mathrm{PC}_{71} \mathrm{BM}$ (1:2 weight ratio)/Ca/Al. This device retained a high $V_{\mathrm{OC}}$ of $0.90 \mathrm{~V}$. Nevertheless, the PCE was not considerably enhanced and was limited to $4.87 \%$ mainly because of moderate $J_{\mathrm{SC}}$ and FF values. This was partially considered as a result of the low $M_{n}$ of DTS- $\mathrm{C}_{6}$-L because $M_{\mathrm{n}}$ is known to influence the photophysical properties of polymers and the morphology of $\mathrm{BHJ}$ films. ${ }^{36}$ The copolymer side chains are also known to have an important role in controlling the film morphology, which determines OPV performance. ${ }^{37}$ Therefore, to obtain a high PCE, we fine-tuned the following: (1) the synthesis of copolymers to obtain a higher $M_{\mathrm{n}}$, (2) the alkyl chain components in the naphtho[2,3-c]thiophene-4,9-dione unit $\left(\mathbf{C}_{4}, \mathrm{C}_{6}, \mathrm{C}_{\mathrm{EH}}\right.$ and $\left.\mathrm{C}_{8}\right)$ (Figure 6a) and (3) the thin-film fabrication process for $\mathrm{BHJ}$ blends with $\mathrm{PC}_{71} \mathrm{BM}^{23}$

The distannylated DTS unit of the Stille-coupling copolymerization component, 4,4-bis(2-ethylhexyl)-2,6-bis(trimethylstannyl)-4H-dithieno $\left[3,2-b: 2^{\prime}, 3^{\prime}-d\right]$ silole (DTS-Sn), was carefully purified by reverse-phase preparative liquid chromatography to guarantee the stoichiometry of DTS-Sn relative to its dibromo counterpart during the copolymerization. As a result, the improved purity of DTS-Sn leads to a drastic increase in the molecular weight of the resulting copolymers. The $M_{\mathrm{n}} \mathrm{s}$ for DTS-C 4 , DTS- $\mathrm{C}_{6}$, DTS- $\mathrm{C}_{\mathrm{EH}}$ and DTS-C $\mathbf{8}_{\mathbf{8}}$ were determined to be $41.5,42.8,53.4$ and $46.3 \mathrm{~kg} \mathrm{~mol}^{-1}$, respectively, from analytical gel permeation chromatography with $\mathrm{CHCl}_{3}$ as an eluent, and the $D_{\mathrm{M}} \mathrm{S}$ were measured to be 2.0, 1.7, 1.7 and 2.0, respectively (Table 1). The differential scanning calorimetry profiles and X-ray diffraction patterns indicated that these copolymers intrinsically adopt an amorphous morphology, regardless of the $M_{\mathrm{n}} \mathrm{s}$ and alkyl chain substituents.

The physical properties of DTS- $\mathrm{C}_{4}$, DTS- $_{6}$, DTS- $_{\mathrm{EH}}$ and DTS- $\mathrm{C}_{8}$ are summarized in Figure $6 \mathrm{~b}$ and Table 1. From the UV-vis spectra, these copolymers exhibited similar spectroscopic shapes and peak wavelengths even as films, which indicates that the alkyl groups in the acceptor units have little influence on the interchain interactions in the solid state. The $\Delta E_{\mathrm{g}}{ }^{\text {opt }}$ s of these copolymers, extracted from the film absorption onset values, are ca. $1.62-1.64 \mathrm{eV}$. The ionization potential of DTS- $\mathrm{C}_{6}$, obtained from PESA, was nearly at the same level as DTS- $\mathrm{C}_{6}-\mathrm{L}$, and the $E_{\mathrm{HOMO}}$ for all the copolymers were determined to be in a narrow range between -5.25 and $-5.33 \mathrm{eV}$. Based on these $E_{\mathrm{HOMO}}$ and $E_{\mathrm{g}}{ }^{\text {opt }}$ values, their $E_{\mathrm{LUMO}}$ were also calculated in a narrow range between -3.63 and $-3.70 \mathrm{eV}$.

To investigate the influence of molecular weights, the photovoltaic properties of DTS- $\mathbf{C}_{6}$ and DTS- $\mathbf{C}_{6}-\mathrm{L}$ were evaluated using $\mathrm{PC}_{71} \mathrm{BM}$ as the acceptor. For an $80-\mathrm{nm}$-thick BHJ film, DTS- $\mathrm{C}_{6}-\mathrm{L}$ delivered a moderate $\mathrm{PCE}$ of $4.55 \%$. In contrast, the $\mathrm{DTS}^{-\mathrm{C}_{6}}$-based device exhibited an improved PCE of $5.21 \%$ (Table 2). This PCE improvement is mainly ascribed to the increased $J_{\mathrm{SC}}$ and $\mathrm{FF}$, which are derived from the morphological change and increased SCLC hole mobility of the BHJ layer $\left(1.0 \times 10^{-4} \mathrm{~cm}^{2} \mathrm{~V}^{-1} \mathrm{~s}^{-1}\right.$ for DTS-C 6 vs $3.4 \times 10^{-5} \mathrm{~cm}^{2} \mathrm{~V}^{-1} \mathrm{~s}^{-1}$ for DTS- $\left.\mathrm{C}_{6}-\mathrm{L}\right)$. Under the same fabrication conditions, DTS- $\mathrm{C}_{\mathrm{EH}}$ exhibited a comparable PCE of $5.15 \%$. In contrast, although the $V_{\mathrm{OC}}$ values were similarly high, the devices with DTS- $\mathrm{C}_{4}$ and DTS- $\mathrm{C}_{8}$ resulted in lower overall efficiencies. This deterioration is due to the decreased FF for DTS- $\mathrm{C}_{4}$ and the reduced $J_{\text {SC }}$ for DTS- $C_{8}$. We attributed the low FF for DTS- $C_{4}$ to its low hole mobility $\left(7.8 \times 10^{-5} \mathrm{~cm}^{2} \mathrm{~V}^{-1} \mathrm{~s}^{-1}\right)$. On the other hand, from the atomic force microscopic measurements, which showed the largest estimated $R_{\mathrm{a}}$ value of $3.2 \mathrm{~nm}$ among these five blend films, we concluded that the relatively high alkyl chain density for DTS-C 8 

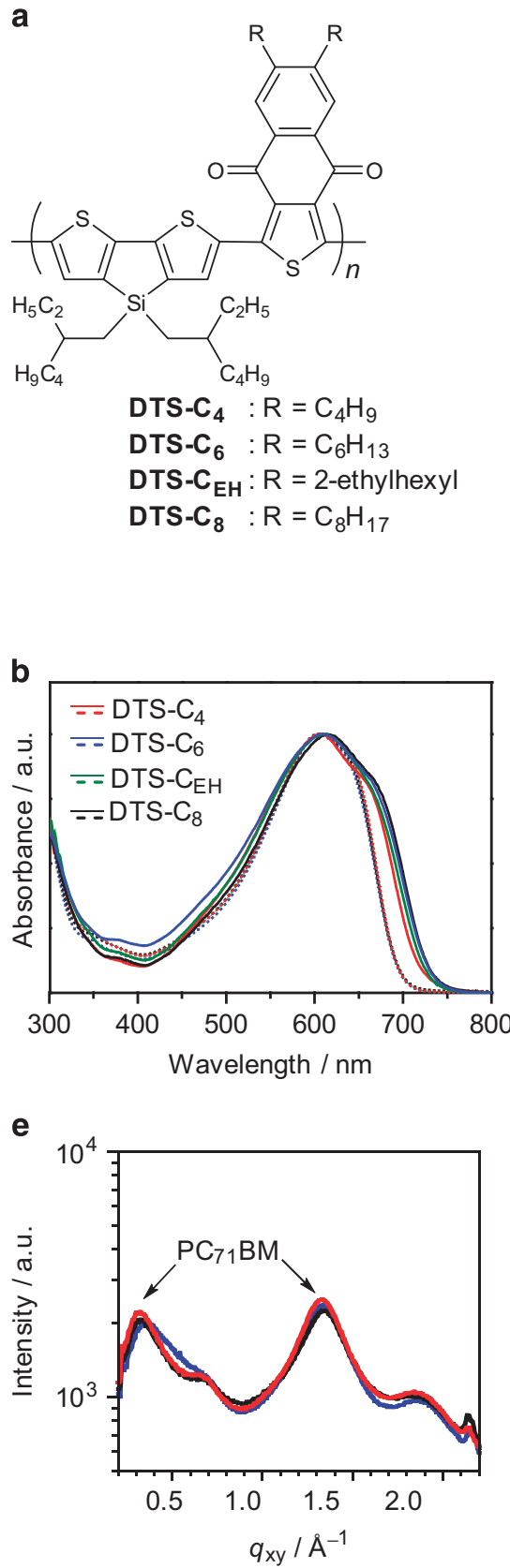

C

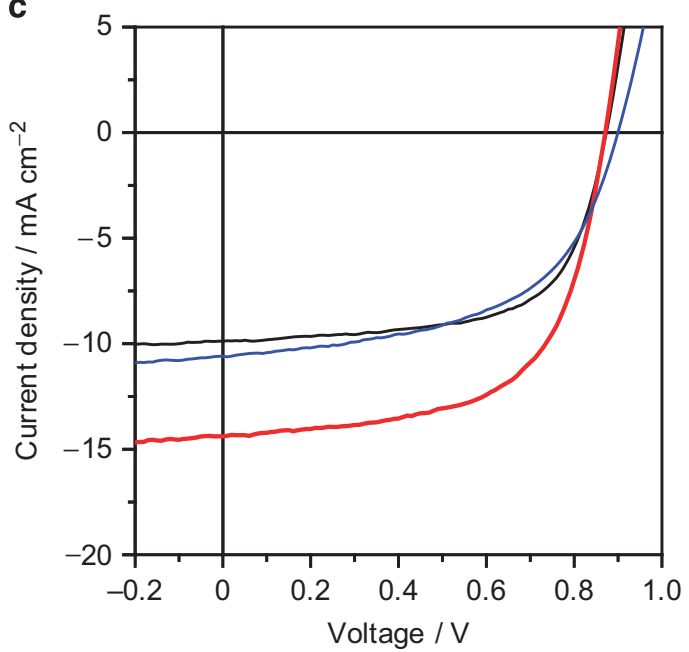

d
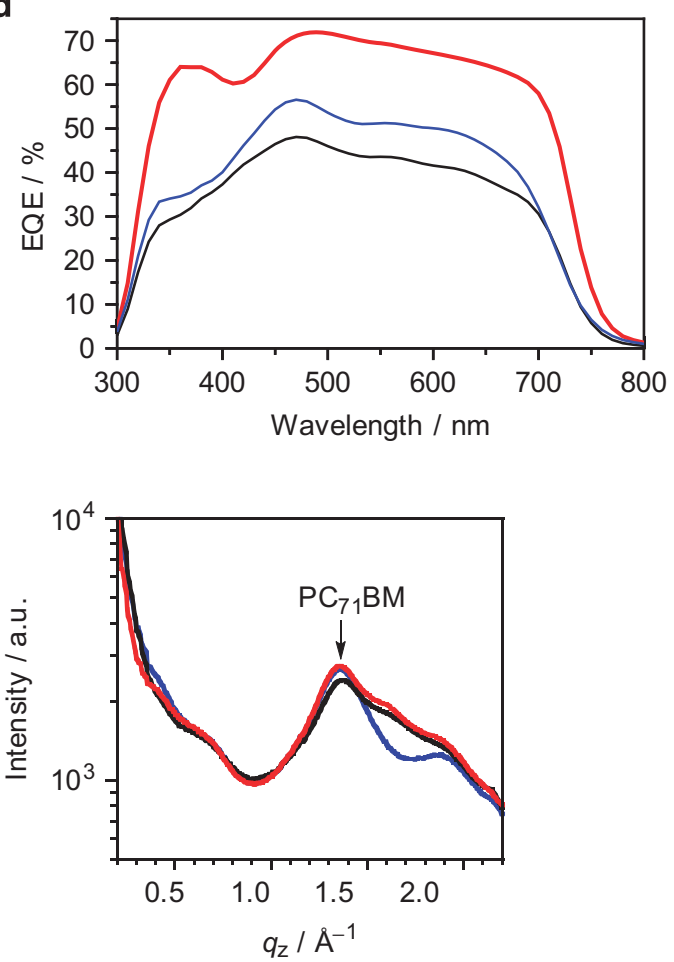

Figure 6 (a) Chemical structures and (b) UV-vis absorption spectra of DTS- $\mathbf{C}_{4}$, DTS- $\mathbf{C}_{6}$, DTS- $\mathbf{C}_{\mathrm{EH}}$ and $\mathbf{D T S}-\mathrm{C}_{8}$ in $\mathrm{CHCl}_{3}$ solution (dashed line) and as films (solid line). (c) Current density-voltage curves and (d) external quantum efficiency spectra of the DTS- $C_{6} / P C_{71} B M$ OPV devices fabricated using 0 -DCB (blue), o-DCB/DIO (black) and o-DCB/CHCl $/ \mathrm{DIO}$ (red). (e) In-plane (left) and out-of-plane (right) two-dimensional grazing incidence X-ray diffraction profiles for the DTS- $C_{6} / \mathrm{PC}_{71} \mathrm{BM}$ blend films fabricated using o-DCB (blue), o-DCB/DIO (black) and o-DCB/CF/DIO (red).

may cause poor intermixing with $\mathrm{PC}_{71} \mathrm{BM}$, which would hamper efficient exciton dissociation and result in low $J_{\mathrm{SC}}$.

We attempted to optimize spin-coating solvents and additives for the DTS- $\mathrm{C}_{6} / \mathrm{PC}_{71} \mathrm{BM}$ blend films to further improve the OPV performance by controlling the film morphology. Upon adding 3\% $(\mathrm{v} / \mathrm{v})$ DIO to the spin-coating solvent (o-DCB), the PCE further increased to $5.56 \%$, which was attributed to the increased FF. The SCLC measurements indicated that the addition of DIO led to an increase in both the hole and electron mobilities without sacrificing the carrier mobility balance (Table 3). When $\mathrm{CHCl}_{3}$ with $3 \% \mathrm{DIO}$ was used as the solvent instead of $o$-DCB with $3 \%$ DIO, the device exhibited a slightly decreased PCE of $5.42 \%$. However, the thicker film
$(190 \mathrm{~nm})$ formed as a result of these fabrication conditions led to a markedly high $J_{\mathrm{SC}}$ of $15.54 \mathrm{~mA} \mathrm{~cm}^{-1}$, which was derived from improved light absorption, whereas FF was considerably reduced owing to the decreased overall conductance. As summarized in Table 3, the SCLC electron mobility of the $\mathrm{CHCl}_{3}$ :DIO-processed film was $7.5 \times 10^{-6} \mathrm{~cm}^{2} \mathrm{~V}^{-1} \mathrm{~s}^{-1}$, which is almost an order of magnitude lower than that of the $o$-DCB:DIO-processed film $\left(3.6 \times 10^{-5} \mathrm{~cm}^{2} \mathrm{~V}^{-1} \mathrm{~s}^{-1}\right)$. To maintain both the high $\mathrm{FF}$ (o-DCB/DIO) and high $J_{\mathrm{SC}}\left(\mathrm{CHCl}_{3} / \mathrm{DIO}\right)$, a ternary solvent composition of $o-\mathrm{DCB} / \mathrm{CHCl}_{3}$ with $3 \% \mathrm{DIO}$ was used in a $4: 1$ volume ratio. The OPV device based on DTS- $\mathrm{C}_{6} / \mathrm{PC}_{71} \mathrm{BM}$ (with a 1:2 weight ratio) exhibited the best PCE of $7.85 \%$ (Figure $6 \mathrm{c}$ ). The external quantum 
Table 3 SCLC mobilities of DTS- $\mathrm{C}_{6} / \mathrm{PC}_{71} \mathrm{BM}$ blend films

\begin{tabular}{lccc}
\hline $\begin{array}{l}\text { Processed } \\
\text { solvent }\end{array}$ & Thickness/nm & $\begin{array}{c}\text { Hole mobilitya/ } \\
\mathrm{cm}^{2} \mathrm{~V}^{-1} \mathrm{~s}^{-1}\end{array}$ & $\begin{array}{c}\text { Electron mobility } \\
\mathrm{cm}^{2} \mathrm{~V}^{-1} \mathrm{~s}^{-1}\end{array}$ \\
\hline o-DCB & 80 & $1.0 \times 10^{-4}$ & $2.9 \times 10^{-5}$ \\
o-DCB:DIO & 82 & $1.6 \times 10^{-4}$ & $3.6 \times 10^{-5}$ \\
$\mathrm{CHCl}_{3}$ :DIO & 190 & $2.3 \times 10^{-4}$ & $7.5 \times 10^{-6}$ \\
o-DCB:CF:DIO c & 79 & $2.0 \times 10^{-4}$ & $7.0 \times 10^{-5}$ \\
\hline
\end{tabular}

Abbreviations: DIO, 1,8-diiodooctane; o-DCB, o-dichlorobenzene; SCLC, space-charge-limited current.

aHuang et al. ${ }^{23}$

efficiency spectrum of this device showed a high photoresponse between 300 and $800 \mathrm{~nm}$ with a maximum value of $70 \%$ at $500 \mathrm{~nm}$ (Figure 6d). In the $o-\mathrm{DCB} / \mathrm{CHCl}_{3} / \mathrm{DIO}$-processed films, the SCLC measurements showed an increase in their hole- $\left(2.0 \times 10^{-4} \mathrm{~cm}^{2} \mathrm{~V}^{-1} \mathrm{~s}^{-1}\right)$ and electron-transporting $\left(7.0 \times 10^{-5} \mathrm{~cm}^{2} \mathrm{~V}^{-1} \mathrm{~s}^{-1}\right)$ characteristics.

Two-dimensional grazing incidence $\mathrm{X}$-ray diffraction was used to further investigate the microstructures of the $o-\mathrm{DCB}, o-\mathrm{DCB} / \mathrm{DIO}$ and $o$-DCB/CF/DIO films. The two-dimensional grazing incidence X-ray diffraction (2D GIXD) profiles are shown in Figure 6e. In all the films, no significant differences were observed in the degree of crystallinity for $\mathrm{PC}_{71} \mathrm{BM}$. In contrast, visible differences can be detected for DTS$\mathrm{C}_{6}$. Thin films fabricated with $o$-DCB do not show the diffraction peaks derived from DTS- $\mathrm{C}_{6}$, which indicates an amorphous nature of the copolymer in this $\mathrm{BHJ}$ film. When the thin films were fabricated using $o$-DCB/DIO, a weak diffraction peak is observed at $1.6 \AA^{-1}$ in the $q_{\mathrm{z}}$ axis. This peak corresponds to the $\pi-\pi$ stacking in DTS- $\mathrm{C}_{6}$. In addition, this peak becomes slightly more intense after $o-\mathrm{DCB} / \mathrm{CF} /$ DIO processing was performed, which indicates an improved ordering of DTS-C 6 . Thus we concluded that the use of the ternary solvent in the amorphous DTS- $\mathrm{C}_{6} / \mathrm{PC}_{71} \mathrm{BM}$ system generates larger domains accompanied by subtly ordered $\pi-\pi$ stacking of DTS- $\mathrm{C}_{6}$ backbones, which may contribute to enhanced carrier mobility and chargeseparation efficiency, and lead to improved photovoltaic performance.

\section{SUMMARY AND OUTLOOK}

In this focused study, we investigated the use of new low band-gap D-A copolymers based on dioxocycloalkene-annelated thiophenes as electron-acceptor units. Our systematic structural modifications of the acceptor units can tune their energy levels and solubility. The development of a series of D-A copolymers based on the combination of these acceptor units with fixed donor DTS or BDT units enabled us to determine the relationship among molecular structures, physical properties and OPV characteristics. These results demonstrate that dioxocycloalkene-annelated thiophene can be a promising electronacceptor unit for D-A-type OPV materials. On the other hand, a noticeable connection between structural variations and the photovoltaic performance was observed, which correlates with the influence of the film morphology and/or carrier mobility on the performance of $\mathrm{BHJ}$ blend films. We expect that OPV performance can be further improved by the precise optimization of both molecular design and thin-film fabrication processes. The key strategy for molecular design involves fine-tuning the electronic structures of dioxocycloalkeneannelated thiophene units and finding appropriate combinations with donor units. For thin-film fabrication, the establishment of novel fabrication techniques that promote the ordering of interchain $\pi-\pi$ interactions in amorphous $\mathrm{D}-\mathrm{A}$ copolymers based on dioxocycloalkene-annelated thiophenes in $\mathrm{BHJ}$ films is essential. Further studies based on these concepts will give us important insight into the structure-property-OPV performance relationships and will accelerate advances in $\mathrm{BHJ}$ solar cells.

\section{CONFLICT OF INTEREST}

These authors declare no conflict of interest.

\section{ACKNOWLEDGEMENTS}

This work was supported by Japan Science and Technology Agency (JST)-PRESTO, MEXT, JSPS and in cooperation with Sumitomo Chemical Co., Ltd. We thank all the co-authors listed in the references. We also thank Mr Takeo Makino for support with synthesis. We are thankful to Professor Yasujiro Murata and Dr Atsushi Wakamiya, both from the Institute for Chemical Research (ICR) in Kyoto University, for the PESA measurements. We are also thankful to Dr Itaru Osaka from RIKEN, for 2D GIXD measurements. This work was partially supported by the Collaborative Research Program of the Institute for Chemical Research, Kyoto University. Thanks are extended to the CAC, ISIR for assistance in obtaining elemental analyses.

1 Dou, L., You, J., Hong, Z., Xu, Z., Li, G., Street, R. A. \& Yang, Y. 25th Anniversary Article: A decade of organic/polymeric photovoltaic research. Adv. Mater. 25 6642-6671 (2013).

2 Krebs, F. F., Espinosa, N., Hösel, M., Søndergaard, R. R. \& Jørgensen, M. 25th Anniversary Article: Rise to power-OPV-based solar parks. Adv. Mater. 26, 29-39 (2014).

3 Hiramoto, M., Fujiwara, H. \& Yokoyama, M. Threelayered organic solar cell with a photoactive interlayer of codeposited pigments. Appl. Phys. Lett. 58, 1062-1064 (1991).

4 Yu, G., Gao, J., Hummelen, J. C., Wudl, F. \& Heeger, A. J. Polymer photovoltaic cells: enhanced efficiencies via a network of internal donor-acceptor heterojunctions. Science 270, 1789-1791 (1995).

5 Heeger, A. J. 25th Anniversary Article: Bulk heterojunction solar cells: understanding the mechanism of operation. Adv. Mater. 26, 10-28 (2014).

$6 \mathrm{Li}, \mathrm{Y}$. Molecular design of photovoltaic materials for polymer solar cells: toward suitable electronic energy levels and broad absorption. Acc. Chem. Res. 45, 723-733 (2012).

7 Wu, J.-S., Cheng, S.-W., Cheng, Y.-J. \& Hsu, C.-S. Donor-acceptor conjugated polymers based on multifused ladder-type arenes for organic solar cells. Chem. Soc. Rev. 44, 1113-1154 (2015).

8 Hou, J. H., Chen, H.-Y., Zhang, S. Q., Li, G. \& Yang, Y. Synthesis, characterization, and photovoltaic properties of a low band gap polymer based on silole-containing polythiophenes and 2,1,3-benzothiadiazole. J. Am. Chem. Soc. 2008 16144-16146 (2008).

9 Hou, J., Chen, H.-Y., Zhang, S., Chen, R. I., Yang, Y., Wu, Y. \& Li, G. Synthesis of a low band gap polymer and its application in highly efficient polymer solar cells. J. Am. Chem. Soc. 131, 15586-15587 (2009).

10 Wienk, M. M., Turbiez, M., Gilot, J. \& Janssen, R. A. J. Narrow-bandgap diketo-pyrrolopyrrole polymer solar cells: the effect of processing on the performance. Adv. Mater. 20, 2556-2560 (2008).

11 Zhang, Y., Hau, S. K., Yip, H.-L., Sun, Y., Acton, O. \& Jen, A. K.-Y. Efficient polymer solar cells based on the copolymers of benzodithiophene and thienopyrroledione. Chem. Mater. 22, 2696-2698 (2010).

12 Chen, H.-Y., Hou, J. H., Zhang, S., Liang, Y., Yang, G., Yang, Y., Yu, L., Wu, Y. \& Li, G. Polymer solar cells with enhanced open-circuit voltage and efficiency. Nat. Photonics 3 , 649-653 (2009).

13 Wang, M., Hu, X., Liu, P., Li, W., Gong, X., Huang, F. \& Cao, Y. Donor-acceptor conjugated polymer based on naphtho[1,2-c:5,6-c]bis[1,2,5]thiadiazole for highperformance polymer solar cells. J. Am. Chem. Soc. 133, 9638-9641 (2011).

14 le, Y., Umemoto, Y., Kaneda, T. \& Aso, Y. Electronegative oligothiophenes based on a hexafluorocyclopentene-annelated thiophene unit. Org. Lett. 8, 5381-5384 (2006).

15 Umemoto, Y., Ie, Y., Saeki, A., Seki, S., Tagawa, S. \& Aso, Y. Electronegative oligothiophenes fully annelated with hexafluorocyclopentene: synthesis, properties, and intrinsic electron mobility. Org. Lett. 10, 1095-1098 (2008).

16 Ie, Y., Umemoto, Y., Okabe, M., Kusunoki, T., Nakayama, K.-i., Pu, Y.-J., Kido, J., Tada, H. \& Aso, Y. Electronegative oligothiophenes based on difluorodioxocyclopenteneannelated thiophenes: synthesis, properties, and n-type FET performances. Org. Lett. 10, 833-836 (2008).

17 le, Y., Okabe, M., Umemoto, Y., Tada, H. \& Aso, Y. Electronegative oligothiophenes having difluorodioxocyclopentene-annelated thiophenes as solution-processable n-type OFET materials. Chem. Lett. 38, 460-461 (2009).

18 le, Y., Nitani, M., Tada, H. \& Aso, Y. Solution-processed n-type organic field-effect transistors based on electronegative oligothiophenes having fully oxo-substituted terthiophenes. Org. Electron. 11, 1740-1745 (2010).

19 le, Y., Yoshimura, A., Takeuchi, S., Osakada, K. \& Aso, Y. Synthesis and properties of polymer having electronegative terthiophene pendants based on cyclopenta[c]thiophene. Chem. Lett. 40, 1039-1040 (2011). 
20 le, Y., Huang, J., Uetani, Y., Karakawa, M. \& Aso, Y. Synthesis, properties, and photovoltaic performance of copolymers based on difluorodioxocyclopentene-annelated thiophene. Jap. J. Apply. Phys. 51, 10 NC08 (2012).

21 Huang, J., le, Y., Karakawa, M. \& Aso, Y. Low band-gap donor-acceptor copolymers based on dioxocylopenta[c]thiophene derivatives as acceptor units: synthesis, properties, and photovoltaic performances. J. Mater. Chem. A 1, 15000-15009 (2013).

22 le, Y., Huang, J., Uetani, Y., Karakawa, M. \& Aso, Y. Synthesis, properties, and photovoltaic performances of donor-acceptor copolymers having dioxocycloalkeneannelated thiophenes as acceptor monomer units. Macromolecules 45, 4564-4571 (2012).

23 Huang, J., Ie, Y., Karakawa, M., Saito, M., Osaka, I. \& Aso, Y. Enhanced photovoltaic performance of amorphous copolymers based on dithienosilole and dioxocycloalkeneannelated thiophene. Chem. Mater. 26, 6971-6978 (2014).

24 Cui, C., Fan, X., Zhang, M., Zhang, J., Min, J. \& Li, Y. A D-A copolymer of dithienosilole and a new acceptor unit of naphtho[2,3-c]thiophene-4,9-dione for efficient polymer solar cells. Chem. Commun. 47, 11345-11347 (2011).

25 Cui, C., Fan, H., Guo, X., Zhang, M., He, Y., Zhan, X. \& Li, Y. Synthesis and photovoltaic properties of D-A copolymers of benzodithiophene and naphtho[2,3-c]thiophene-4, 9-dione. Polym. Chem. 3, 99-104 (2012).

26 Chen, X., Liu, B., Zou, Y., Tang, W., Li, Y. \& Xiao, D. Copolymers from naphtho[2,3-c] thiophene-4,9-dione derivatives and benzodithiophene: synthesis and photovoltaic applications. RSC Adv. 2, 7439-7448 (2012).

27 Qian, D., Ye, L., Zhang, M., Liang, Y., Li, L., Huang, Y., Guo, X., Zhang, S., Tan, Z. \& Hou, J. Design, application, and morphology study of a new photovoltaic polymer with strong aggregation in solution state. Macromolecules 45, 9611-9617 (2012).

28 Qian, D., Ma, W., Li, Z., Guo, X., Zhang, S., Ye, L., Ade, H., Tan, Z. \& Hou, J. Molecular design toward efficient polymer solar cells with high polymer content. J. Am. Chem. Soc. $135,8464-8467$ (2013).

29 Kim, B.-G., Ma, X., Chen, C., Ie, Y., Coir, E. W., Hashemi, H., Aso, Y., Green, P. F., Kieffer, J. \& Kim, J. Energy level modulation of HOMO, LUMO, and band-gap in conjugated polymers for organic photovoltaic applications. Adv. Funct. Mater. 3, 439-445 (2013).

30 Owczarczyk, Z. R., Braunecker, W. A., Oosterhout, S. D., Kopidakis, N., Larsen, R. E., Ginley, D. S. \& Olson, D. C. Cyclopenta[c]thiophene-4,6-dione-based copolymers as organic photovoltaic donor materials. Adv. Energy Mater. 4, 1301821 (2014).

31 Oosterhout, S. D., Kopidakis, N., Owczarczyk, Z. R., Braunecker, W. A., Larsen, R. E., Ratcliffb, E. L. \& Olsona, D. C. Integrating theory, synthesis, spectroscopy and device efficiency to design and characterize donor materials for organic photovoltaics: a case study including 12 donors. J. Mater. Chem. A 3, 9777-9788 (2015).

32 Zhang, M., Guo, X., Ma, W., Ade, H. \& Hou, J. A large-bandgap conjugated polymer for versatile photovoltaic applications with high performance. Adv. Mater. 27, 4655-4660 (2015).

33 Zhou, H., Yang, L., Stoneking, S. \& You, W. A weak donor-strong acceptor strategy to design ideal polymers for organic solar cells. ACS Appl. Mater. Interfaces 2, 1377-1383 (2010).

34 Peet, J., Kim, J. Y., Coates, N. E., Ma, W. L., Moses, D., Heeger, A. J. \& Bazan, G. C. Efficiency enhancement in low-bandgap polymer solar cells by processing with alkane dithiols. Nat. Mater. 6, 497-500 (2007).

35 Huo, L., Hou, J., Chen, H.-Y., Zhang, S., Jiang, Y., Chen, T. L. \& Yang, Y. Bandgap and molecular level control of the low-bandgap polymers based on 3,6-dithiophen-2-yl-2, 5-dihydropyrrolo[3,4-c]pyrrole-1,4-dione toward highly efficient polymer solar cells. Macromolecules 42, 6564-6571 (2009).

$36 \mathrm{Li}$, W., Yang, L., Tumbleston, J. R., Yan, L., Ade, H. \& You, W. Controlling molecular weight of a high efficiency donor-acceptor conjugated polymer and understanding its significant impact on photovoltaic properties. Adv. Mater. 26, 4456-4462 (2014).

37 Cabanetos, C., Labban, A. E., Bartelt, J. A., Douglas, J. D., Mateker, W. R., Fréchet, J. M. J., McGehee, M. D. \& Beaujuge, P. M. Linear side chains in benzo[1,2-b:4,5- $\left.b^{\prime}\right]$ dithiophene-thieno[3,4-c]pyrrole-4,6-dione polymers direct self-assembly and solar cell performance. J. Am. Chem. Soc. 135, 4656-4659 (2013). 